\title{
The impact of drought on phenotypic characters of five advance bread wheat genotypes
}

\author{
Muslim Qadir ${ }^{1,2 *}$, Xuechun Wang ${ }^{2}$, Abdul Hameed Baloch ${ }^{1}$, Iftekhar \\ Ahmed Baloch ${ }^{3}$, Muhammad Azeem ${ }^{1}$, Muhammad Imran ${ }^{1}$ and \\ Muhammad Saleem ${ }^{1}$ \\ 1. Faculty of Agriculture, Lasbela University of Agriculture, Water and Marine sciences, Lasbela, Baluchistan, \\ 74200-Pakistan \\ 2. School of life science and engineering, Southwest University of Science and Technology, Mianyang, Sichuan \\ 621000-People's Republic of China \\ 3. Govt. Degree College Khanozai, Balochistan-Pakistan \\ *Corresponding author's email: msmirwani22@gmail.com \\ Citation
}

Muslim Qadir, Xuechun Wang, Abdul Hameed Baloch, Iftekhar Ahmed Baloch, Muhammad Azeem, Muhammad Imran, and Muhammad Saleem. The impact of drought on phenotypic characters of five advance bread wheat genotypes. Pure and Applied Biology. Vol. 7, Issue 2, pp635-642. http://dx.doi.org/10.19045/bspab.2018.70079

Received: $18 / 11 / 2017$

Revised: 04/05/2018

Accepted: 08/05/2018

Online First: 12/05/2018

\section{Abstract}

The current study is an effort to identify the best wheat genotype, which can tolerate drought in arid environmental conditions of Lasbela district, Balochistan. For this purpose, five genotypes of wheat, viz., Amber, Mehran, Khirman, Imdad-05 and Sehar-2006 were selected. These five wheat genotypes seeds were sown in winter of 2015-16 at Lasbela University campus for 45 days. The biomass, leaf size, leaf weight and moisture constituents of leaves were collected when these varieties started to show the signs of drought stress in the form of wilting. The results showed that the Sehar-2006 is a promising genotype when grown in Lasbela's local environmental condition compared with other genotypes. On the other hand, Mehran is one most vulnerable genotype when grown in this region. Three genotypes (Imdad-05, Khirman and Amber) showed mix response in relation to water stresses. The research highlighted that Sehar-2006 is the best species to be cultivated by the farmers and it can provide good vigor and high production for future development.

Keywords: Advance bread genotypes; Impact of drought on wheat; Physiological traits; Wheat

\section{Introduction}

Wheat (Tritium aestivum $\mathrm{L}$ ) belonging to the family Poaceae, is a self-pollinated and the most important cereal crop of the world. It is a staple food and provides about $35 \%$ of food as consumed by the world population [1]. It is the utmost extensively cultivated food crop of the world. Its adaptation to diverse climatic conditions is a key feature to make it a remarkable crop; which has important role in world economy. It is thought to have originated on the Eurasian continent, a starting point from where man spread it throughout the world, including China and central Europe [2]. Wheat is providing 68\% of energy and stands second among cereal crops with respect to Asia and more specifically in the south Asian region [3]. 
Wheat is the cheapest source of calories, protein, and carbohydrates in human nutrition. It is grown as a rain-fed as well as irrigated grown crop [4].

The challenge to maintain regional food security in poorest regions on earth requires an annual rise in wheat production from 2.0 $2.5 \%$ [5]. Moderate to severe water stress extremely affects various physiological traits in wheat, such as dry matter production, assimilating area, relative water content (RWC) and chlorophyll content. Reduced plant size, leaf area, and leaf area index are a major mechanism for moderating water use and reducing injury under drought stress [6]. It is revealed that varieties, with higher leaf turgor and RWC are more droughts tolerant and give higher yield than others $[7,8]$. Physiological changes in traits such as stomatal density, weight, area and relative leaf water content have been considered as important criteria for yield progress $[9,10]$. Significant differences could be found among tillers and the availability of water to wheat plant during yield formation process [11]. It has been reported that 65 million ha of wheat area is subjected to drought stress throughout the world [5]. Climate change threatens to reduce crop production [12]. To accelerate yield improvement, physiological traits at all levels of integration need to be considered in breeding [13, 14].

In Pakistan major cultivated area is devoted to wheat and occupies i.e $70 \%$ of Rabi and $37 \%$ of total cropping area [15]. Wheat is the leading food grain of Pakistan occupying the largest area under single crop and contributes $10.0 \%$ to the value added in agriculture and 2.1 percent to GDP. Rain-fed wheat accounts $20 \%$ area in Pakistan [16]. Wheat production in Baluchistan is 871,300 tones/year and the area under cultivation is nearly 382,940 hectares [17]. Balochistan, the largest but least populated province of Pakistan faces challenges relevant with water scarcity.
Ecologically, the province Balochistan is classified from semi-arid desert to arid zone. The aim of this study is to evaluate the physiological characterization of advance bread wheat genotypes and to determine the effectiveness and reliability of physiological traits for screening drought tolerant genotypes of bread wheat. It is an effort to identify the best wheat genotype, which can tolerate drought in arid environmental conditions of Lasbela district, Balochistan.

\section{Materials and methods}

The present research was carried out at the experimental field in the Department of Plant Breeding \& Genetics, Faculty of Agriculture, Lasbela University of Agriculture, Water and Marine Sciences (LUAWMS), Baluchistan, $\left(66^{0} 30^{\prime}\right.$ East longitude and $25^{\circ} 67^{\prime} \mathrm{N}$ latitude).The experiments were laid-out in Randomized Complete Block Design (RCBD) with three replications during Rabi season of 2015-16, in order to assess the physiological traits of advance bread wheat genotypes from drought as climatic limiting factor. The experiment was carried out in open field with proper arrangements for controlling the precipitation during the experiment. It is a matter of fact that there is very little precipitation in Lasbela. We didn't have any precipitation during the experiment. Seeds were collected from Agriculture research center Saryab road Quetta. In this context, bread wheat was sown in $25^{\text {th }}$ November 2015. Five wheat genotypes viz., Amber, Mehran, Khirman, Imdad-05 and Sehar-2006 were examined for simple flag leaf weight, flag leaf area, specific flag leaf weight and relative water content after drought treatments. At the first sign of wilting (one month after sowing) these morphological traits were noted on five wheat genotypes.

\section{Data collection}

Three leaves per genotype, per replication, were collected for the determination of simple flag leaf weight, and Flag Leaf areas. 
The leaf weight and leaf area of five wheat genotypes were measured by electronic devices for the determination of specific flag leaf weight. The relative water content was measured in freshly collected leaves from five wheat genotypes. For this purpose, fresh leaves were weighed (FW) and placed for an hour in distilled water. Subsequently these leaves were again weighed for evaluating the turgid weight (TW). The samples were autoclaved at $60^{\circ} \mathrm{Cfor}$ eighteen hour, and then weighed for dry weight (DW). The relative water content was calculated by using the following formula:

Relative Water Content $(\%)=\mathrm{FW}-\mathrm{DW} /$ TW - DW ×100 [18]

Where

$\mathrm{FW}=$ Fresh weight,

DW $=$ Dry weight and

TW $=$ Turgid weight .

\section{Data analysis}

The morphological traits were analyzed by using simple one-way ANOVA and mean values among different wheat varieties were compared by using Tukey HSD test $(p<0.05)$ with the help of SPSS Base 16.0 [19].

\section{Results and discussion}

The traditional agricultural practices in Lasbela district depended upon seasonal rain and local formers used to grow droughttolerant pulses and grains. However, during last quarter of $20^{\text {th }}$ century the local formers shifted from traditional agricultural practices to cash crops and high-carbohydrate grains such as wheat due to availability of reliable energy resources. Therefore, growing wheat varieties in this district to some extent is a recent phenomenon.

The wheat genotypes were sown on 25 November at LUAWMS Experimental field (Rabi season, 2015-16). Generally, during this month of the year, the local weather of Lasbela district, Balochistan, has shown positive impacts on germination and emergence of wheat varieties. In this context five different wheat varieties were studied in
Lasbela University campus for evaluating their potential in this area. The results of this study showed that the five different wheat varieties behaved differently based on morphological characteristics. The simple flag leaf weight and relative water content showed significant differences $(p<0.001)$ among five varieties of wheat (Table 1, subsection a, and d). Similarly, the simple flag leaf area also showed significant difference among five wheat varieties $(\mathrm{p}<$ 0.05, Table 1 subsection b). However, specific flag leaf weight $(\mathrm{mg})$ did not show any differences among five varieties (Table, 1 , subsection c). These morphological traits were further evaluated among wheat varieties with the help of Tukey HSD test and results of this test are presented in figures 1-4. When simple flag leaf weight (mg) was analyzed among five varieties, the results showed that wheat variety Sehar-2006 possessed highest value (432.44 \pm 6.55$)$ compared with Mehran $(223.73 \pm 1.52)$ and therefore Sehar-2006 is significantly different $(\mathrm{p}<0.05)$ compared with rest of varieties (Figure 1). However, there is no significant differences observed among Amber (339.77 \pm 4.7), Kirman $(322.55 \pm 2.23)$ and Imdad-05 (322.90 \pm 0.57) (Figure 1). Similarly, when Flag leaf area $(\mathrm{cm} 2)$ was compared among wheat varieties it is observed that Mehran produced smaller blades $(12.19 \pm 1.37)$ compared with Kirman which produced longer leaf blade $(23.97 \pm 3.38)$. However, there were no significant differences observed among Amber-05 (19.08 \pm 1.65), Sehar-2006 (21.02 $\pm 3.35)$ and Imdad (14.98 \pm 0.77) (Figure 2). Moreover, when data obtained for the RWC were studied among wheat varieties, the results showed that Amber-05 exhibited lowest relative water content $(36.89 \pm 3.11)$ compared with rest of varieties and therefore significantly varied compared with other wheat varieties when grown in Lasbela district environmental condition (Figure 4). Despite these discrepancies prevailing 
among wheat varieties when compared the above mentioned morphological traits, the specific flag leaf weight $(\mathrm{mg})$ did not show any significant differences when these varieties compared with the help of Tukey test $(\mathrm{p}<0.05)$ (Figure 3$)$.

In present study four different morphological traits relevant with photosynthesis were studied among five different wheat varieties for selecting the suitable candidate for Lasbela's arid environmental condition. Keeping in view, water as a limiting factor, results obtained from these morphological traits may be helpful in selecting the promising varieties which are suitable for Lasbela district. It was one of the reasons that RWC was studied in these wheat varieties because RWC plays a major role in leaf tissue turgor pressure. This turgor pressure ultimately maintains the activities of leaf resulting to high rate of photosynthesis [20]. Under water stresses condition, RWC is a valid indicator in leaves of selected genotypes [21]. The selected genotypes have expressive response to RWC under abiotic stresses especially in drought stress. Working in Ethiopian arid environmental condition,
Bogale et al. [22] had highlighted that under water stress conditions RWC decreased up to $36.7 \%$. The maximum RWC however was recorded in drought tolerant wheat cultivars compared with susceptible cultivars which showed less water retention potential than tolerant cultivars. Farquhar et al. [23] also suggested that RWC is closely related to water supply to the leaf and its transpiration rate. Jones et al. [24] recommended that RWC improves the ability of a plant to recover from stress and consequently produces higher grain yield. Leaf Area is another important aspect to be considered in crop growth because it plays an important role in photosynthesis [25]. The decline in Leaf area following the flag leaf stage might be attributed to aging of leaves, leaf senescence and thermal stress [26]. Flag leaf area has positive correlation with grain yield in many cereal crops but more leaf area might cause more water losses due to more evapotranspiration from the surface. Therefore, optimum leaf area is required for carrying out enough photosynthesis to run the essential processes of plant [27].

Table 1. One way-ANOVA for different morphological traits of five genotypes

\begin{tabular}{|c|c|c|c|c|c|c|}
\hline Source of variance & Subsection & $d f$ & SS & MS & F value & $p \leq 0.05$ \\
\hline Simple Flag Leaf weight (mg) & \multirow{4}{*}{ A } & & & & & \\
\hline Genotypes (varieties) & & 4 & 65921.31 & 16480.32 & 378.0 & $0.0001 * *$ \\
\hline Error (Residual) & & 10 & 435.98 & 43.59 & --- & --- \\
\hline Total & & 14 & 66357.30 & --- & --- & --- \\
\hline Flag leaf area & \multirow{4}{*}{ B } & & & & & \\
\hline Genotypes (varieties) & & 4 & 259.51 & 64.87 & 3.86 & $0.038^{*}$ \\
\hline Error (Residual) & & 10 & 167.89 & 16.78 & --- & --- \\
\hline Total & & 14 & 427.39 & --- & --- & --- \\
\hline Specific flag leaf weight (mg) & \multirow{4}{*}{$\mathrm{C}$} & & & & & \\
\hline Genotypes (varieties) & & 4 & 45.90 & 11.47 & 1.07 & NS \\
\hline Error (Residual) & & 10 & 106.32 & 10.63 & & \\
\hline Total & & 14 & 152.22 & & & \\
\hline Relative water content. & \multirow{4}{*}{ D } & & & & & \\
\hline Genotypes (varieties) & & 4 & 4671.39 & 1167.84 & 20.72 & $0.0001 * *$ \\
\hline Error (Residual) & & 10 & 563.62 & 56.36 & & \\
\hline Total & & 14 & 5235.01 & & & \\
\hline
\end{tabular}

$\mathrm{NS}=$ non-significant, $*=p \leq 0.05, * *=p<0.001$

Note: Subsection A is the Simple Flag Leaf weight; B is the Flag leaf area; C is the Specific flag leaf weight; D Subsection showing the Relative water content. 


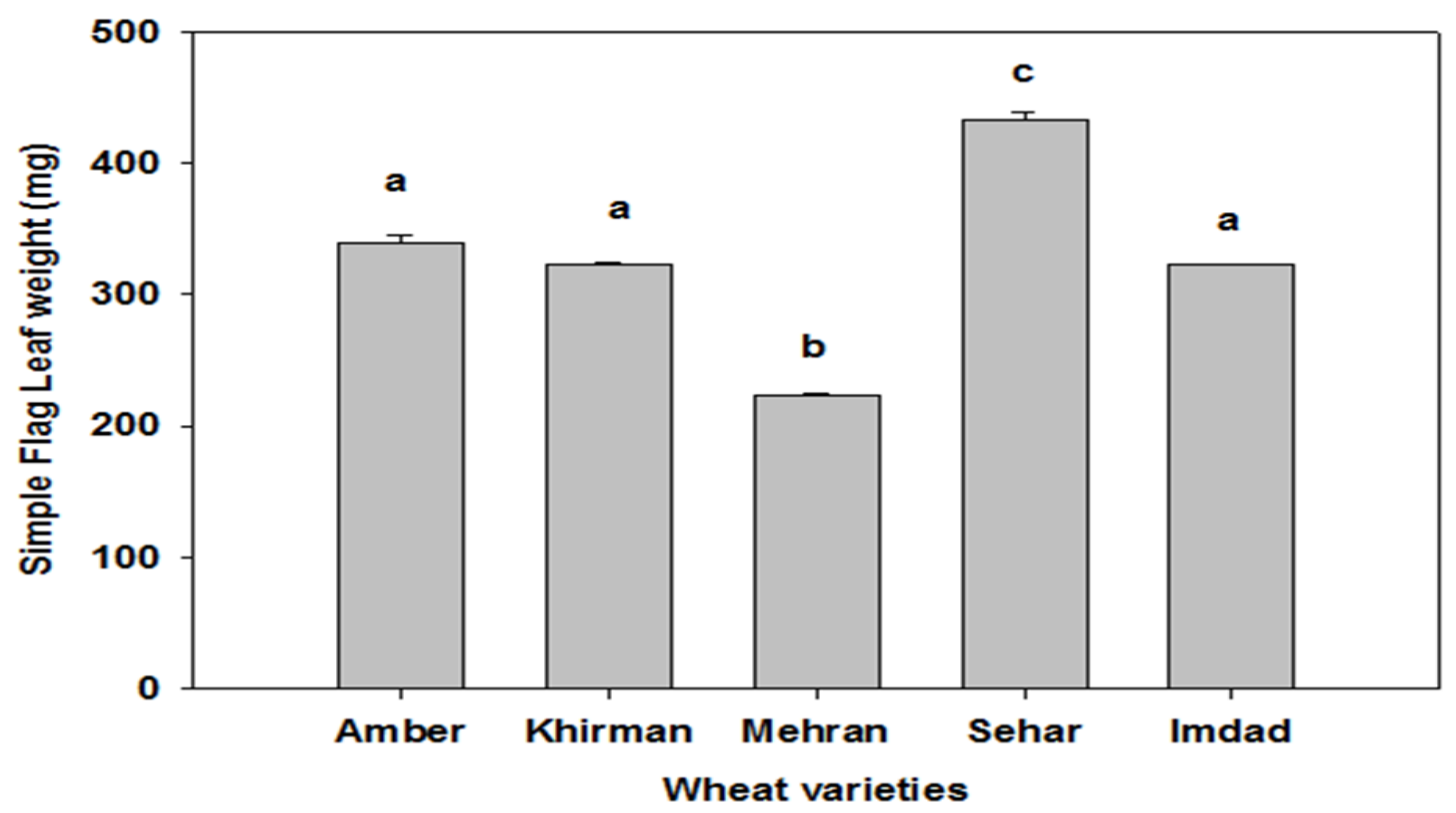

Figure 1 . Identification and variation of all five wheat varieties based on data of simple Flag Leaf weight (The values are the means+ SE. Bar values followed by the same letters are not significantly different at $p<0.05$, based on Tukey HSD test)



Figure 2. Identification and variation of all five wheat varieties based on data of Flag leaf area (The values are the means+ SE. Bar values followed by the same letters are not significantly different at $p<0.05$, based on Tukey HSD test) 


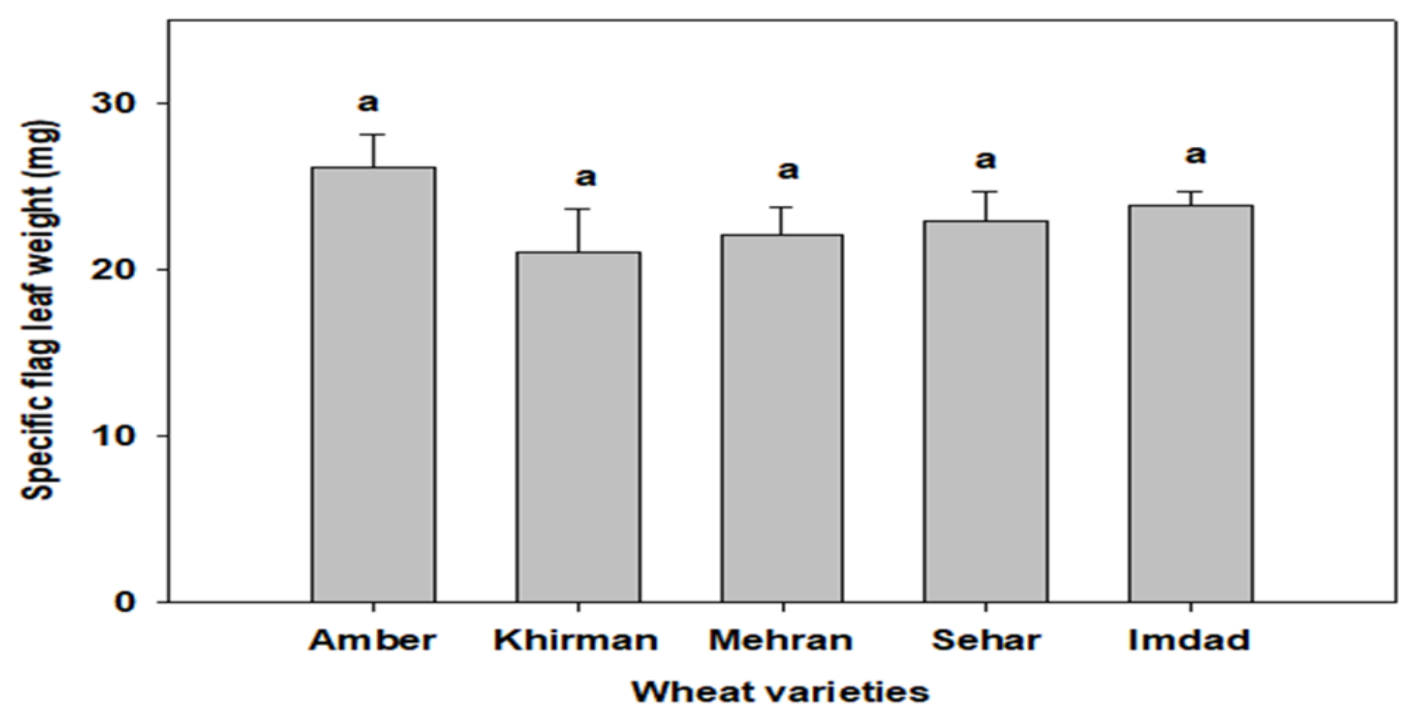

Figure 3. Identification and variation of all five wheat varieties based on data of specific Flag leaf weight (mg). (The values are the means+ SE. Bar values followed by the same letters are not significantly different at $\mathbf{p}<$ 0.05, based on Tukey HSD test)



Figure 4. Identification and variation of all five wheat varieties based on data of Relative Water content (\%). (The values are the means+ SE. Bar values followed by the same letters are not significantly different at $p<$ 0.05, based on Tukey HSD test) 


\section{Conclusion}

The above-mentioned four aspects were taken into account to guage the effect of drought on the five different genotypes of wheat when grown in arid enviromental condition of Lasbela district. The five geneotypes, Amber, Mehran, Khirman, Imdad-05 and Sehar-2006 play a major role in food secuity of Pakistan. However, there is a paucity of scientific knowledge on impacts of arid environmental conditions particularly of Balochistan province on the yield of these varieties. Therefore the current study was aimed to figureout the best suited wheat genotype for Balochistan province in general and Lasbela district in particular. Taking into consideration these morphological traits it is therefore suggested that among these five genotypes the most promising were Sehar2006 followed by Amber, Kirman, Imdad-05 and Mehran. Sehar-2006 showed highest R.W.C, area and weight which are more in resisting the drought condition. While Mehran showed poor response when grown in Lasbela district, therefore, this study suggests that this genotype should not be considered for further study. It is opted to mention here that these are the preliminary results of an extended research project which is still underway in Lasbela University. Therefore, the impact of drought on final yield of these five genotypes is important to be studied for making a clear decision for selecting these varities.

\section{Acknowledgement}

The authors are highly indebted to the Faculty of Agriculture at Lasbela University of Agriculture, Water and Marine Sciences for provision of facilities, Laboratory equipment's, good environment and guidance during present research work. Besides this we are also very thankful to the anonymous reviewers for their valuable suggestions which enabled us to present the refined version of this work.

\section{Authors' contributions}

Conceived and designed the experiments: $\mathrm{M}$ Qadir, X Wang, Performed the experiments: M Qadir \& X Wang, Analyzed the data: M Qadir, M Azeem, M Imran \& M Saleem, Contributed materials/ analysis/ tools: $\mathrm{AH}$ Baloch \& IA Baloch, Wrote the paper: M Qadir.

\section{References}

1. Mohammadi-joo S, Mirasi A, Saeidiaboeshaghi R \& Amiri M (2015). Evaluation of bread wheat (Triticum aestivum L.) genotypes based on resistance indices under field conditions. Int J Biosci 6(2): 331-337.

2. Haider $N$ (2012). Evidence for the origin of the $\mathrm{B}$ genome of bread wheat based on chloroplast DNA. Turk J Agric 36: 1325.

3. Shewry PR (2009). Drought on bread wheat crop. J of Experimental Bot 60(6): 1537-1553.

4. Monneveux P, Jing R \& Misra SC (2012). Phenotyping for drought adaptation in wheat using physiological traits. Frontiers in Physiology 3: 429.

5. Food and Agriculture Organization (FAO) (2013). The State of Food Insecurity in the World. The multiple dimensions of food security. Rome, FAO.

6. Mitchell JH, Siamhan D, Wamala MH, Risimeri JB, Chinyamakobvu E, Henderson SA \& Fukai, S (1998). The use of seedling leaf death score for evaluation of drought resistance of rice. Field crops research 55(1-2): 129-139.

7. Akram M (2011). Growth and yield components of wheat under water stress of different growth stages. Bangladesh $J$ Agril Res 36(3): 455- 468.

8. Khakwani AA, Dennet MD \& Munir M (2011). Drought tolerance screening of wheat varieties by inducing water stress conditions. Songklanakarin J. Sci. Technol., 33(2), 135-142. 
9. Blum A (2005). Drought resistance, water-use efficiency, and yield potential - are they compatible, dissonant, or mutually exclusive. Aust J Agric Res 56: 1159-1168.

10. Khokar MI \& da Silva JAT (2012). Evaluation of drought tolerance and yield capacity of barley (Hordeum vulgare) genotypes under irrigated and water-stressed conditions. Pak J Agric Sci 49: 307-313.

11. Zhang J, Wang JA, Dang JY \& Zhang DY (2010). Difference of grain yield and quality between the main stems and tillers of wheat. $J$ of Triticeae Crops 30: 526-528.

12. Challinor AJ, Watson J, Lobell DB, Howden SM, Smith DR \& Chhetri N (2014). A meta-analysis of crop yield under climate change and adaptation. Nat Clim Chang 27: 1-5.

13. Chapman SC, Chakraborty S, Dreccer MF, Howden SM P.2012. Plant adaptation to climate change opportunities and priorities in breeding. Crop Pasture Sci 63: 251-268.

14. Long SP, Marshall-Colon A, Zhu XG (2015). Meeting the global food demand of the future by engineering crop photosynthesis and yield potential. 161: 56-66.

15. Farooq AM, Yaqoob I \& Sadozai KN (2007). Varietal adoption effect on wheat crop production in irrigated areas of NWFP. Sarhad J Agri 23(3): 807-814.

16. Ahmad M, Akram Z, Munir M \& Rauf $M$ (2006). Physio-morphic response of wheat genotypes under rainfed conditions. Pak J Bot 38(5): 1697-1702.

17. Directorate of crops and reporting services, Agriculture department, Qauetta, 2015-2016.

18. Gavuzzi P, Rizza F, Palumbo M, Campanile RG, Ricciardi GL \& Borghi
B (1997). Evaluation of field and laboratory predictors of drought and heat tolerance in winter cereals. Can J Plant Sci 77: 523-531.

19. SPSS Base 16.0 2007. SPSS ${ }^{\circledR}$ software product, SPSS Inc., Chicago, IL, USA.

20. Thomas JA, Jaffrey AC, Atsuko K \& David MK (2005). Regulating the proton budget of higher plant photosynthesis. Proc Natl Acad Sci USA 102: 97099713.

21. Merah O (2001). Potential importance of water status traits for durum wheat improvement under Mediterranean conditions. J Agric Sci 137: 139-145.

22. Bogale A, Tesfaye $K \&$ Geleto T (2011). Morphological and physiological attributes associated to drought tolerance of Ethiopian durum wheat genotypes under water deficit condition. $J$ of Biodiversity and Environ Sci 1(2): 2236.

23. Farquhar GD, Wong SC, Evans JR \& Hubic KT (1989). Photosynthesis and gas exchange. Plants under Stress. Cambridge University Press, UK. 47-69.

24. Jones HG, Flowers TJ \& Jones MB (1989). Plants under Stress. Cambridge University Press, Cambridge, UK.

25. Siddique MRB, Hamid $H$ \& Islam MS (2000). Drought stress effects on water relations of wheat. Bot Bull Acad Sci 41: 35-39.

26. Dalirie MS, Sharifi RS \& Farzaneh S (2010). Evaluation of yield, dry matter accumulation and leaf area index in wheat genotypes as affected by terminal drought stress. Not Bot Hort Agrobot Cluj 38 (1): 182-186.

27. Khaliq I, Irshad A \& Ahsan M (2008). Awns and flag leaf contribution towards grain yield in spring wheat (Triticum aestivum L.). Cer Res Commun 36: 6576. 